\title{
Prolonged luteal lifespan and pseudopregnancy in Asian elephants (Elephas maximus)
}

Imke Lueders $^{\mathrm{a}^{*}}$, Cheryl Niemueller ${ }^{\mathrm{b}}$, Hanspeter W. Steinmetz ${ }^{\mathrm{c}}$, Tim Bouts $^{\mathrm{d}}$, Charlie Gray ${ }^{\mathrm{e}}$, Tobias Knauf-Witzens ${ }^{\mathrm{f}}$, Kazuyoshi Taya ${ }^{\mathrm{g}}$, Gen Watanabe ${ }^{\mathrm{g}}$, Yuki Yamamoto ${ }^{\mathrm{g}, \mathrm{h}}$, Ann-Kathrin Oerke $^{\mathrm{i}}$

${ }^{a}$ Endocrine Research Laboratory, Department of Anatomy and Physiology, Faculty of Veterinary Science, University of Pretoria, Private Bag X04, Onderstepoort 0110, South Africa

${ }^{b}$ Conservation Biology Laboratory, 6 Kingfisher International, Inc., Stouffville, Ontario, Canada

${ }^{c}$ Chester Zoo, Moston Rd, Upton-by-Chester, Chester CH2 IEU, UK

${ }^{d}$ Park Pairi Daiza, Domaine de Cambron in B-7940 Brugelette, Belgium

${ }^{e}$ African Lion Safari, 1386 Cooper Road, Cambridge, ON, N1R 5S, Canada

${ }^{f}$ Wilhelma, Zoologisch-Botanischer Garten, 70342 Stuttgart, Germany

${ }^{g}$ Tokyo University of Agriculture and Technology, Tokyo, Japan

${ }^{h}$ Graduate School of Environmental and Life Science, Okayama University, 700-8530, Okayama, Japan

i German Primate Center, European Elephant Service, 37077 Goettingen

* corresponding author: Endocrine Research Laboratory, Department of Anatomy and Physiology, Faculty of Veterinary Science, University of Pretoria, Private Bag X04, Onderstepoort 0110, South Africa

E-mail address:imke.lueders@geolifes.com

\section{Highlights}

- Persistent corpora lutea and prolonged luteal lifespan occur in elephants.

- First confirmation of the occurrence of hyperprolactinemiae in Asian elephants.

- Multiple corpora lutea may be active and secrete progestagens for up to 16 months.

\begin{abstract}
Pseudopregnancy is a physiological occurrence in mammals which exhibit copulation induced ovulation, but is rarely described in spontaneous ovulating species. Here we report 3 cases of prolonged luteal lifespan in non-pregnant Asian elephants (Elephas maximus). Case 1 was a 25-year-old female that had produced three calves previously; Case 2 was a nulliparous and 32-y.-o. at the start of the pseudopregnancy episode; and Case 3 occurred in a 49-y.-o., nulliparous elephant. Serum progesterone metabolite concentrations remained elevated for 10 months in Case 1. Urinary progestagens were high for $>16$ months in Case 2 and for five months in Case 3. In Case 1, multiple persistent corpora lutea were visualized monthly by ultrasound. In all three cases, uterine leiomyoma were present and progestagen levels dropped spontaneously. Case 1 elephant became pregnant 3 years later, whilst Case 2 resumed cycling normally, and Case 3 continued with another prolonged luteal phase before ovaries were
\end{abstract}


downregulated purposely. The examples reported here show that constantly high progestagen levels may not always be indicative of pregnancy in elephants. The reasons for prolonged luteal lifespan remain elusive, although serum prolactin concentrations measured in Case 1 were elevated compared to previous reports and two other herd mates. Furthermore, all three elephants showed varying degrees of uterine pathologies. We argue that the resulting damage to the endometrium may have led to a reaction similar to implantation, which includes prolactin secretion. Prolactin may exert luteotropic properties and is thought to initiate luteal rescue during pregnancy in elephants.

Keywords: Elephant; Corpus luteum; Pregnancy; Leiomyoma; Progesterone; Prolactin

\section{Introduction}

Pseudopregnancy or "false pregnancy" is a state of a female mammal expressing clinical or subclinical signs of gravidity without actually being pregnant. Everett (1961) defined pseudopregnancy as the occurrence of any prolonged functional luteal phase in a nonpregnant cycle. However, the symptoms of overt pseudopregnancy are similar to those of an actual pregnancy and may include udder development and lactation, maternal and "nesting" behavior and weight gain (Gobello et al., 2001a; Sobrinho, 2003). In the covert pseuopregnancy, on the other hand, no clinical signs appear other than persistence of corpora lutea, together with elevated progesterone and even prolactin levels.

Pseudopregnancy occurs commonly in induced ovulators, which undergo a prolonged phase of luteal activity following sterile mating. It has been suggested to be a mechanism to increase evolutionary fitness in some species, e.g. mongoose and wolfs, whereby nonreproducing females nurse the offspring of relatives (Creel and Montfort, 1991; Concannon et al., 2009). But it also occurs in solitary species such as most felids, in which the duration of pseudopregnancy is usually about $60-65 \%$ of the actual gestation length and results from corpus luteum formation after non-fertile copulation, or sometimes spontaneous ovulation (Tsutsui \& Stabenfeld 1992). Like felids, pseudopregnancy is known primarily in other copulation-induced ovulators such as mustelids (Murphy, 1989), some ursids (Clamon Schulz et al., 2003; Willis et al., 2011), and several laboratory animal species (rats, mice, rabbits, hamsters: Hilliard, 1973). Apart from canids, where overt pseudopregnancy is a physiological 
phenomenon (Concannon et al., 2009), pseudopregnancy occurs only occasionally in spontaneously ovulating species. Reports exist on swine (DeHoff et al., 1986), some primates (Kasza, 1979; Guedes and Young, 2004) and humans (Manzi et al., 1995). In such spontaneous ovulators studied to date, cyclical luteal lifespan is only extended once maternal recognition of pregnancy took place (Heap et al., 1989), with canids being the big exception to this general rule. In the latter, luteolysis after a non-conceptual ovulation does not exist and the canine corpora lutea persist for an entire pregnancy lifespan, independently of the presence or absence of a conceptus. In other species, in pregnancy an embryonic signal is necessary to prevent the corpora lutea from regressing (as reviewed by Roberts et al., 1996). This signal usually consists of a specific protein secreted by the early embryo and /or the interface of maternal and embryonic connection (Roberts et al., 1996).

The elephant maternal recognition of pregnancy signal is unknown, although placental lactogens and prolactin (PRL) appear to play important roles in the process (Yamamoto et al., 2011). Luteogenesis in elephants appears to differ from all other mammals studied to date. Elephants have a long estrus cycle of up to 16 weeks which includes a luteal phase of 6-10 weeks (Brown et al., 1999; Lueders, 2018). Thus, elephants show the longest regular luteal phases during the estrus cycle of any mammal studied to date (Lueders et al., 2010a). In addition to the ovulatory corpus luteum, between 1 and 10 accessory corpora lutea (CLs) have already developed from luteinized unovulated follicles (LUF) prior to ovulation of the dominant follicle (Lueders et al, 2010a). All the CLs start to regress gradually at around 35-45 days post ovulation (p.ov.), starting with the accessory CLs. Following conception however, luteal rescue occurs at around 45-55 days p.ov., and all CLs start to enlarge to become significantly bigger than during a non-pregnant luteal phase (Lueders et al., 2012). This is coincidental with the first ultrasonographic appearance of the embryonic vesicle at around day 45 p. ov., and it is accompanied by a pronounced rise in serum progestagens concentrations (Lueders et al., 2012). At the same time, the trophoblast of the conceptus begins to secrete placental lactogens and possibly prolactin itself (Yamamoto et al., 2011). It is very likely to be the luteotropic stimulus involved in luteal rescue and in stimulating the secondary growth of the already formed CLs and maintenance of their secretory function throughout gestation (Lueders et al., 2012, Yamamoto et al., 2011).

Pregnancy diagnosis in captive elephants is usually made by weekly measurement of progestagen concentrations from urine or serum and recording elevated concentrations for $>16$ weeks are usually indicative of pregnancy (Lueders, 2018). In the present study, 
however, elevated serum and urinary progestagen concentrations were not associated with pregnancy in three Asian elephants (Elephas maximus). In all three females, the presence of persistent corpora lutea and progestagen concentrations above baseline for 20-64 weeks in the absence of a conceptus was confirmed. Here we describe overt and covert pseudopregnancy in Asian elephants and on this basis, discuss the mechanism of luteal rescue and the possible role of prolactin in luteal prolongation in the absence of pregnancy. We also discuss the endocrine differences between Asian and African (Loxodonta africana) elephants.

\section{Material and methods}

\subsection{Elephants}

The three adult Asian elephant females were kept in different Western zoological facilities together with other females and were hormonally and ultrasonographically monitored as part of the routine health and/or breeding management (Table 1). Case 1 was captive born, whereas Case 2 and Case 3 were wild caught. Case 1 had raised three calves prior to her episode of pseudopregnancy (PP), but the other two females were nulliparous. For comparison, serum progestagen and prolactin levels measured in two additional cycling females, aged 16 and 17 years and housed together with Case 1, were included in this study (control Group 2). Examinations of the animals were carried out in accordance with the EU Directive 2010/63/EU for animal experiments and the National Institutes of Health guide for the care and use of Laboratory animals (NIH Publications No. 8023, revised 1978).

Table 1 Overview of pseudopregnancy (PP) cases in three Asian elephants (Elephas maximus) and life history information. NM: natural mating; AI: artificial insemination.

\begin{tabular}{|l|l|l|l|l|l|l|l|l|}
\hline $\begin{array}{l}\text { Elephant } \\
\#\end{array}$ & $\begin{array}{l}\text { Year } \\
\text { of } \\
\text { birth }\end{array}$ & $\begin{array}{l}\text { Age when } \\
\text { PP } \\
\text { occurred }\end{array}$ & $\begin{array}{l}\text { Bull } \\
\text { held in } \\
\text { facility }\end{array}$ & $\begin{array}{l}\text { No. of } \\
\text { previous } \\
\text { full term } \\
\text { pregnancies }\end{array}$ & $\begin{array}{l}\text { Number of } \\
\text { conceptions }\end{array}$ & $\begin{array}{l}\text { Length of PP } \\
\text { episode } \\
\text { (months) }\end{array}$ & $\begin{array}{l}\text { Uterine } \\
\text { pathology }\end{array}$ & $\begin{array}{l}\text { Weekly } \\
\text { Samples for } \\
\text { progestagen } \\
\text { analysis }\end{array}$ \\
\hline$\# 1$ & 1985 & 25 & Yes & 3 & $4(\mathrm{NM})$ & 11 & yes & Serum \\
\hline$\# 2$ & 1982 & 32 & Yes & 0 & $1(\mathrm{AI})$ & 16 & yes & Urine \\
\hline$\# 3$ & 1967 & 49 & No & 0 & 0 & 5 & yes & Urine \\
\hline
\end{tabular}

\subsection{Ultrasound}

Transrectal ultrasound to visualize the uterus and ovaries was performed as described by Lueders et al., 2010a. Females were assessed initially while standing and thereafter in lateral or sternal recumbence to increase visibility of the uterus. Case 1 was examined 
ultrasonographically twice each month before, during and after the PP period. Case 2 and 3 were examined two times during and after the PP period.

\subsection{Sample collection}

To monitor reproduction, in Case 1 and in the two normally cycling elephants of Group 2, weekly blood samples were taken from the ear vein. In Case 2 and 3, weekly urine samples were obtained for progestagen analysis. Serum or urine samples were stored frozen at $-20^{\circ} \mathrm{C}$ until analyzed.

Serum samples of Case 1 and Group 2 were shipped frozen and assayed in Japan with Convention on International Trade in Endangered Species of Wild Fauna and Flora (CITES) export permit no. 10CA00584/CWHQ and import permit no. 12JP/AB000001.

\subsection{Progestestagen enzyme-immunoassays}

Two different enzyme immuno assays (EIA) were used to measure progestagen concentrations in either elephant serum (Case 1) or urine (Cases 2 and 3) as previously described by Lueders et al., 2010a; 2011 and Niemuller et al.1993, respectively.

The EIA used for serum, cross-reacted with native progesterone and several progesterone metabolites (Graham et al., 2001). The progesterone CL425 antibody and the conjugate were supplied by Coralie Munro, University of California, Davis, CA, USA. Its limit of sensitivity was $0.06 \mathrm{ng} / \mathrm{ml}$ and the intra- and inter-assay coefficients of variation were $<15 \%$. The urine EIA measured primarily concentrations of pregnantriol (P3), the primary progesterone metabolite excreted in the urine of Asian elephants (Niemueller et al., 1993).

\subsection{Prolactin radio-immunoassay}

For serum prolactin measurements in Case 1 and control Group 2, the heterologous $125^{\mathrm{I}}$ double-antibody radioimmunoassay (RIA) previously published for African and Asian elephants was employed (Yamamoto et al., 2010, Yamamoto et al., 2011). Additionally, two normally cycling Asian elephant females (Group 2) at the same facility as Case 1 were 
monitored by analyzing weekly serum samples during three consecutive estrus cycles in the same period.

The measurement method for PRL in elephant serum was constructed using a heterologous RIA system and an anti-human PRL rabbit sera (NIDDK- ant-hPRL-3), iodinated ovine PRL (NIDDK-oPRL-I-2), ovine PRL standard (NIDDK-RP-2) and goat anti-rabbit gamma globulin (ARGG). The intra- and inter-assay coefficients of variation were 4.26 and $8.72 \%$, respectively

\subsection{Estrous cycle stage determination}

The follicular phase (low progestagen) and the luteal/pseudopregnancy phase (elevated progestogen) were determined based on the progestogen concentration measured in serum (Case 1) or urine (Case 2,3). Individual baseline progestagen levels were established by methods described previously (Brown et al., 1999).

\section{Results: Case histories}

Based on elevated progestagen values measured from weekly serum (Case 1, Fig.1 a.) or urine samples (Case 2 and Case 3, Fig. 1 b. and c.), three cases of prolonged luteal lifespan without existing conception were found in Asian elephants. In all three cases, progesterone went eventually back to baseline.

\subsection{Case 1}

This Asian elephant aged 25 years and had given birth previously to three calves (Table 1). Six months prior to the event of prolonged luteal lifespan, the female had conceived a $4^{\text {th }}$ time, but experienced pregnancy loss at 120 days of gestation as documented previously (Lueders et al., 2010b). Two weeks after fetal death, progestagen concentrations dropped to baseline, a new ovulation occurred after an apparently normal follicular phase length and a normal luteal phase occurred subsequently as seen by elevated serum progestagen (Fig. 1 a.) and ultrasound monitoring of the ovaries. After this apparently normal estrus cycle, the next luteal phase was markedly extended. Serum progestagen concentrations remained elevated for 11 consecutive months (Fig. 1a.), although this female had no access to a breeding male. 


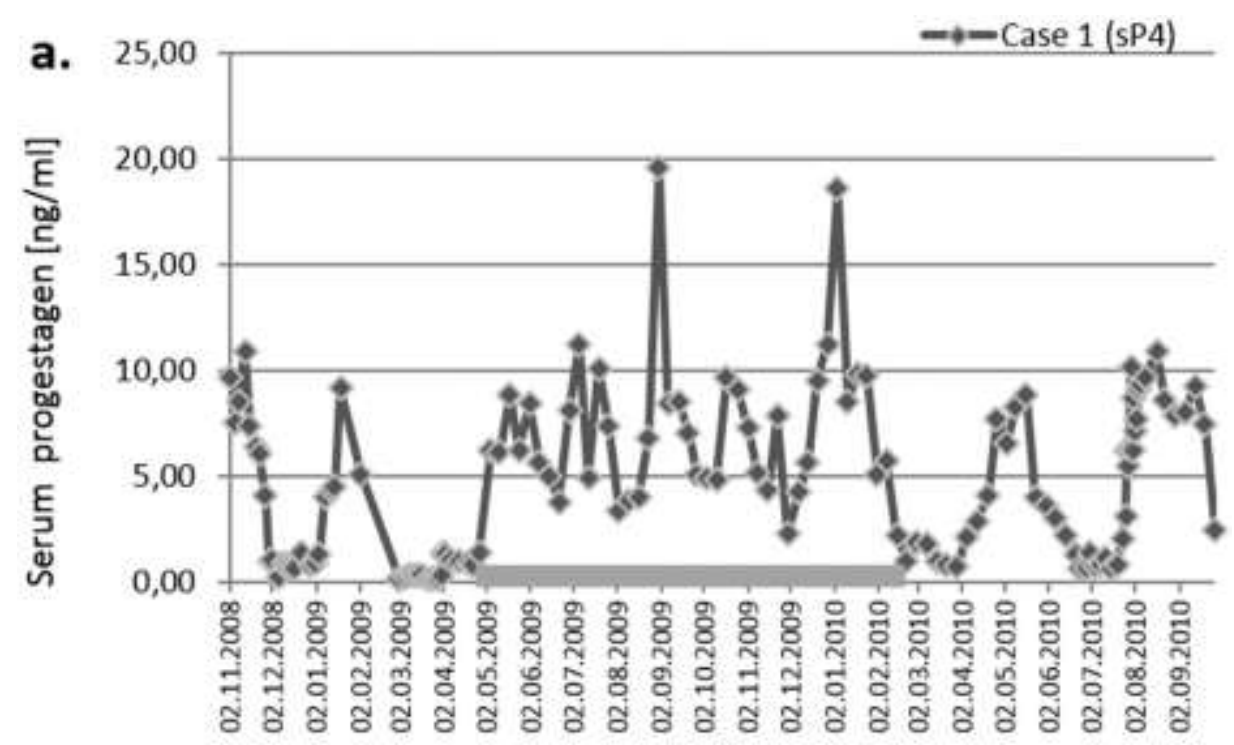

b.
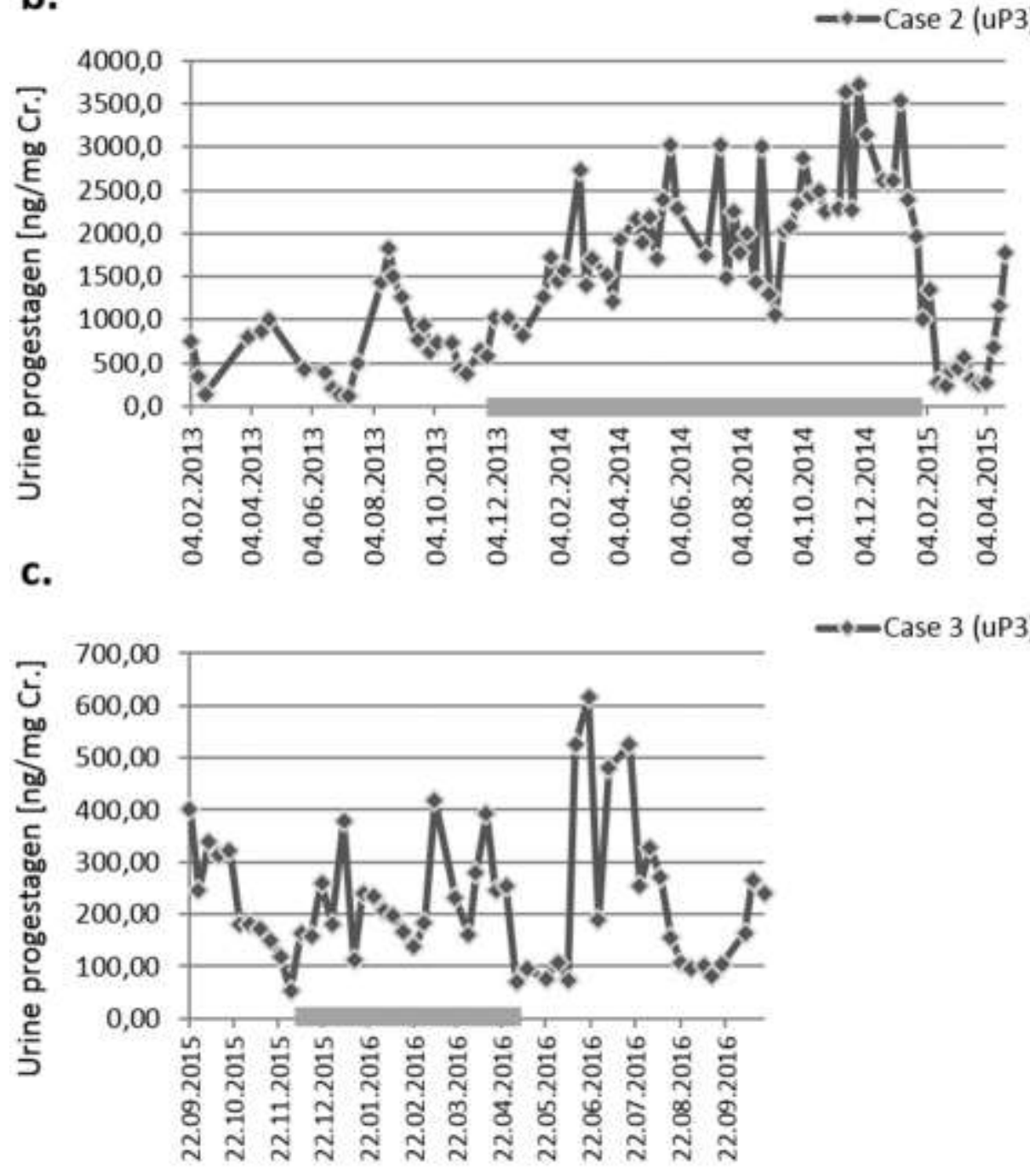

$\mathbf{m}-$ Case 3 (uP3)

Date

Fig.1. Individual serum (a.) and urinary (b.,c.) progestagen profiles of three Asian elephants (Elephas maximus) with extended luteal function. Bar on x-axis marks the timespan of pseudopregnancy. sP4 (serum progestagen); uP3 (urinary pregnantriol). 
Ultrasound examinations of the ovaries revealed a total of 14 persisting corpora lutea (CL), which remained present in number and size throughout the observation period.

Several smaller to medium sized leiomyoma were present in the uterus (Fig. 2 a.) as well as a small site with a highly echoic endometrium around $1 \mathrm{~cm}$ in diameter (Fig. 2 b.).

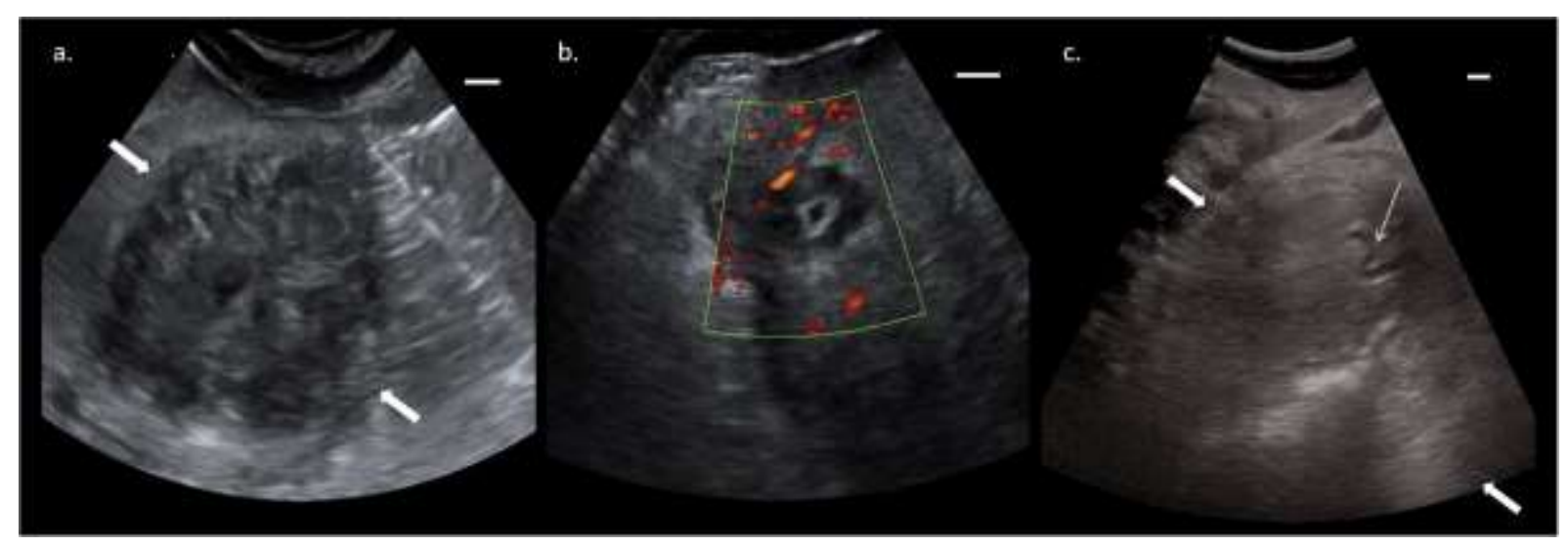

Fig. 2. Transrectal ultrasound images from Asian elephant (Elephas maximus) uteri: a. Destruction of the uterine horn and normal uterine cross section by a mass, likely to be a leiomyoma $(\rightarrow)$ in elephant of Case 1 ; b. the activated endometrium (hyperechoic ring) of the same elephant (Case1); c. a large uterine mass (arrows), likely a leiomyoma, in Case 3, small arrow: blood vessel within the mass. Bars to the right indicate $1 \mathrm{~cm}$.

In addition, seven weeks after last ovulation, the female showed signs of breast development, and milk production, which ultimately progressed to mastitis that required local and systemic antibiotic treatment to cure.

Serum prolactin concentration (sPRL) during the entire observation period (November 2008-April 2010) averaged $22.63 \mathrm{ng} / \mathrm{ml}$ with occasional spikes $>500 \mathrm{ng} / \mathrm{ml}$ in Case 1 (Fig. 3). Although the average prolactin level during the phase of pseudopregnancy (May 2009-March 2010) was $7.49 \pm \mathrm{ng} / \mathrm{ml}$ (range 0.29-36.9 $\mathrm{ng} / \mathrm{ml}$ ), six measurements during this period exceeded $20 \mathrm{ng} / \mathrm{ml}$. By comparison, sPRL of two other, non-pregnant, cyclic Asian elephant females of the same facility (Group 2) averaged $1.3 \pm 0.62 \mathrm{ng} / \mathrm{ml}$ and $2.1 \pm 0.98 \mathrm{ng} / \mathrm{ml}$, respectively with no measured spikes (Fig. 3). 


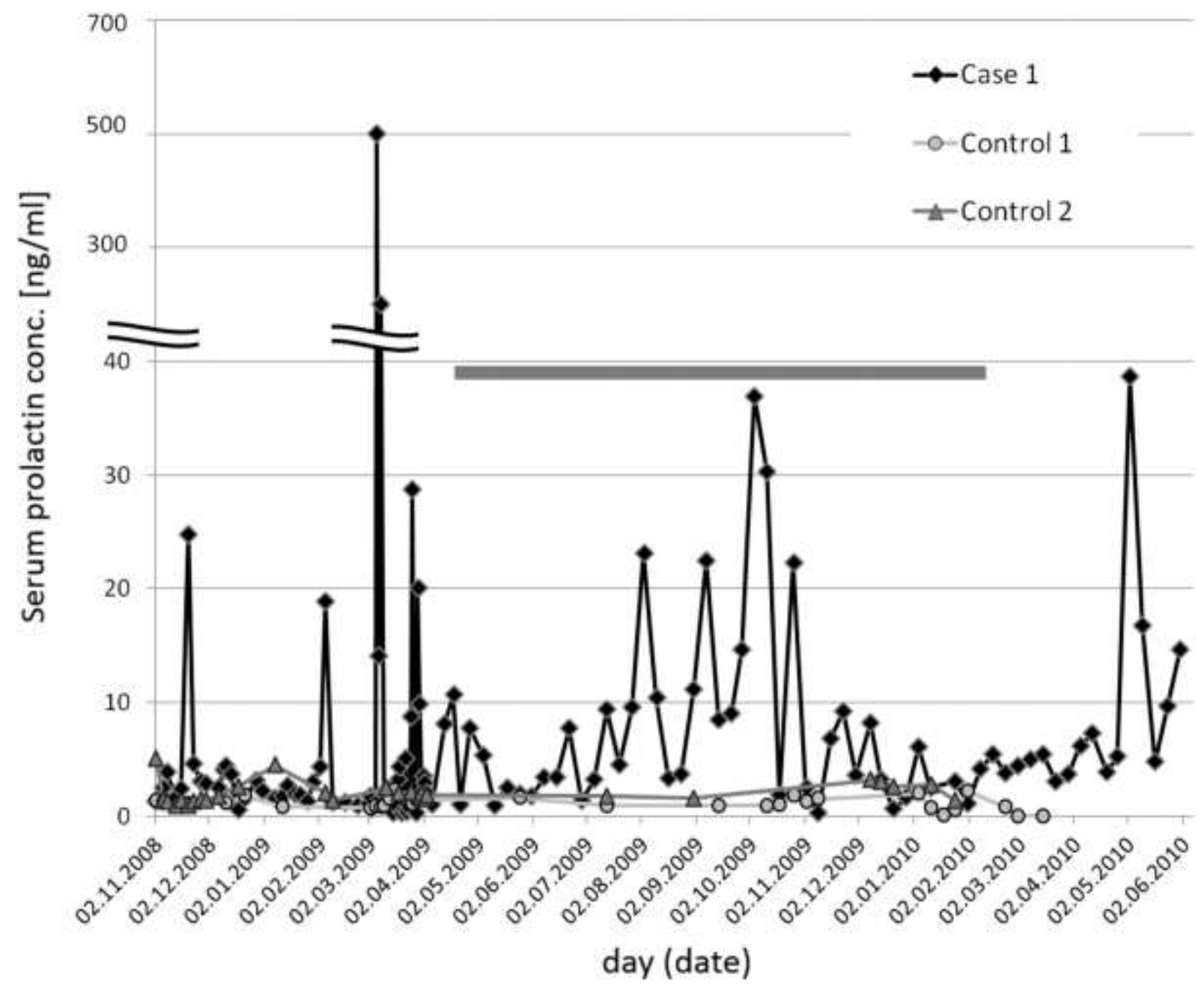

Fig. 3. Serum prolactin concentrations (sPRL) of the Asian elephant (Elephas maximus) Case 1 prior and during the pseudopregnancy episode (grey bar) compared to regular cycling Asian elephants (Control 1 and 2)

\subsection{Case 2}

This 32 years old female Asian elephant showed regular estrus cycles, as monitored by urinary progestagen (P3) measurements. Several attempts to artificially inseminate this elephant failed some 10 years previously, with only one occasion of early pregnancy resulting in spontaneous embryonic loss. At the time of PP, she had access to an inexperienced male, which showed some sexual interest and attempted to mate, but did not succeed technically. Noteworthy, six weeks after ovulation and the rise in P3 levels, this female showed lethargia and discomfort. A blood sample revealed low grade anemia, leukopenia, neutropenia, monocytopenia and eosinophilia. Serum calcium was low and $\mathrm{Ca}: \mathrm{P}$ ratio was inverted. Lucerne and minerals were added to the diet. 
When then P3 levels remained elevated for $>4$ months, the care team became optimistic that pregnancy had occurred despite no full penetration has been observed by mating attempts of the bull. Transrectal ultrasound was carried out during month 5 after the rise in P3, but no conceptus could be detected. The ovaries showed two large CLs on the right ovary. After 15 months of elevated urinary P3 concentrations, there were still no external signs of pregnancy (no weight gain or breast development). The urinary P3 levels eventually went down to baseline after 16 months (Fig. 1 b.). Six weeks later, another ultrasound was performed. At this time, several smaller uterine pathologies were seen such as single cysts of the endometrium and a generally hyperechoic uterine mucosa. Regressing luteal structures were also observed on both ovaries, matching those in number and distribution seen previously. Fresh follicles were also observed. But again, no fetal structures were seen. Case 2 resumed cycling normally and ovulated 6 weeks after the PP period ended (Fig. 1 b.).

\subsection{Case 3}

This third case of prolonged luteal lifespan was found in a 49-y.o., nulliparous female (Fig. $1 \mathrm{c}$.), which was housed together with another aged female in the absence of a bull. During a routine reproductive ultrasound assessment multiple leiomyoma, measuring up to $20 \mathrm{~cm}$ in diameter, were found in the uterus showing vascularization (Fig. 2 c.). The ovaries were active and contained 4 corpora lutea indicating that Case 3 was in the luteal phase at the time of examination. However, urinary P3 concentrations remained high for five months in total. When urinary P3 finally decreased, another ultrasound examination revealed that the previously detected CLs were regressing and confirmed that the same CLs had persisted for the whole period, confirming an extended luteal lifespan.

\section{Discussion}

We found extended luteal persistence and function beyond the reported normal 8 - 10 week lifespan in the absence of pregnancy in 3 Asian elephants. Several potential causes of PP in spontaneously ovulating mammals and humans have been reported including mycotoxins (Chang et al, 1979), psychogenic factors (Sobrinho, 2003), a suckling stimulus on the nipples (Seyle \& McKeown, 2015), and hormone producing, extra-uterine tumors (Matsushima et al., 1980). 
In our 3 cases, the underlying cause of the PP remains unclear, but none of the above mentioned causes were detected. None of the females received any medication, was obese or stressed during the observation period which could explain any hormonal imbalances or elevated PRL. We suspect a "false stimulus", similar to the maternal recognition of pregnancy signal, may be involved, which prevented CLs from regression. This signal may have been caused by uterine irritation, exactly during the period of maternal recognition, which sets on around 40 to 50 days post ovulation in elephants (Lueders et al., 2012). This irritation may be caused by either i.) endometrial inflammation and/or ii.) endometrial destruction, possibly even causing a decidual reaction-like process in the uterus.

In mares, insertion of glass or plastic balls into the uterus seems to mimic the embryo induced signal and results in prolonged luteal lifespan (Del Alamo et al., 2008). Also administration of plant oils into the uterine lumen of mares has been shown to induce pseudopregnancy by inhibiting luteolysis (Wilsher \& Allen, 2011). Similarly, in a study on domestic cats suffering uterine inflammation, prominent, active corpora lutea on the ovaries were associated with adenomatotic proliferative changes in the superficial and glandular epithelium of the uterus and with myometrial hyperplasia (Lawler et al., 1991). In an earlier study on rats, uterine trauma and treatment with hormones such as placental lactogen supported a normal decidual reaction in the traumatized uterine horn and vaginal mucification, all associated with pseudopregnancy (Josimovich, 1968).

In Case 1, at around 3 months of elevated serum progestagen, a site in the uterus was detected resembling remarkably such a decidual reaction in humans with a highly echoic endometrium (Day \& Jurkovic, 2012), but looked unlike the early pregnancy in elephants (Lueders et al., 2010b; 2012; Fig. 2 b), which depicts as a clear round vesicle already at 50 days (Hildebrandt et al., 2007). Likewise, Case 2 showed some form of immune response six weeks into pseudopregnancy, expressed by illness and blood parameter changes. If combined with the right timing (around six weeks after ovulation), a localized endometrial inflammatory reaction might well trigger a pregnancy-like feedback and initiate luteal rescue.

Leiomyomata are commonly found in Asian elephants and their incidence can exceed 25\% of the adult females (Montali et al., 1997). These leiomyomata are known to grow towards the endometrium, sometimes breaking into the uterine lumen. They may cause discomfort and vestibular discharge and bleeding. Although very speculative, a similar scenario, involving a combination of mechanical and traumatic stimuli to the endometrium induced by growth of leiomyoma, may have occurred in the elephants described here. The physical mass of the 
leiomyoma pressing against or pushing through the endometrium may mimic the mass of the conceptus. The trauma caused by myometrial tumours growing into the uterine lumen may stimulate an inflammatory response, similar to a normal decidual reaction. Combined with the right timing of such an event during the mid-late luteal phase, we hypothesize that a maternal recognition of pregnancy signal may be mimicked.

In elephants, the nature of the maternal recognition of pregnancy signal and the mechanism by which it prolongs luteal lifespan is not well understood, but is likely associated with the secretion of placental lactogens and PRL (Yamamoto et al., 2011, 2012, 2017; Lueders et al., 2012). It has been shown in elephants that multiple CLs persist in the ovaries during the entire 22 months long gestation. These CLs grow in size significantly at about 45 days post ovulation (Lueders et al., 2012), coincidentally with commencing implantation and the immunocytochemical appearance of placental lactogens in trophoblast cells (Yamamoto et al., 2011). A recent study demonstrated that African elephant CLs express prolactin receptors and that the placenta of African elephants secretes prolactin itself (Yamamoto et al., 2017). The placental prolactin shows exactly the same amino acid sequence as the pituitary prolactin, underlining its potential role in pregnancy recognition and maintenance in elephants.

It is well established that prolactin concentrations in both Asian and African elephants rise several hundred folds above non-pregnant values during months 4 - 6 of gestation and they remain 2.5 -10-fold higher at least until 10 days after parturition (Brown and Lehnhardt, 1997, Yamamoto et al., 2012). Prolactin and placental lactogens have luteotrophic properties in a number of species and are associated with pseudopregnancy in the rat (Smith et al., 1976) and dog (Gobello et al., 2001b). Placental lactogen and PRL are thought to act luteotropic in the elephant (Brown and Lehnhardt, 1997; Yamamoto et al., 2011; Lueders et al., 2012). The measurement of high prolactin concentrations in Case 1 may support a PRL involvement in CLs function maintenance.

Brown and Lehnhardt (1997) reported mean PRL levels in cycling Asian elephants at $4.4 \pm$ $0.6 \mathrm{ng} / \mathrm{ml}$, ranging between 0.6 and $11.6 \mathrm{ng} / \mathrm{ml}$ in the luteal phase. We can confirm these values for the two healthy and normally cycling elephants in Group 2 in this study. In contrast, Case 1 exceeded such moderate values with PRL spikes up to $37.0 \mathrm{ng} / \mathrm{ml}$ during the PP period with occasional spikes already occurring in the measurement period six months prior the phase of PP. These PRL values match reference levels during early pregnancy in Asian elephants and in lactating elephants as reported previously (Brown and Lehnhardt, 1997). Occasionally, PRL spikes of around 300-500 ng/ml were detected just prior to the PP 
episode in Case 1 (Fig. 3). Such high concentrations are unusual and are reported only after month 6 of gestation in Asian elephants (Brown and Lehnhardt, 1997). Hyperprolactinemia in African elephants was characterized by PRL concentration of $20-40.0 \mathrm{ng} / \mathrm{ml}$ in the same study. Our Case 1 showed overt signs of pseudopregnancy, with breast development, milk secretion and, finally, mastitis; these symptoms have been described in association with hyperprolactinemia in African elephants (Yamamoto et al., 2010). However, in African elephants, elevated PRL levels are associated with complete absence of cyclicity ("flatlining"; Dow and Brown, 2012; Yamamoto et al., 2010). In contrast to Asian elephants with no clear pattern during the estrus cycle (Carden et al., 1998), in African elephants PRL levels are higher during the follicular phase compared to the luteal phase (Bechert et al, 1999). In the current report, elevated PRL concentrations may have been associated with prolongation of luteal lifespan in Case 1. These results also point to a slight difference in the role of PRL secretion in the two elephant species. What ultimately triggered the heightened secretion of PRL and its origin remains unclear however.

It is known that human leiomyoma -derived smooth muscle cells secrete prolactin (PRL, Nowak et al., 1993). Such PRL production is higher than that in normal myometrial cells and is independent of steroid hormones (Daly et al., 1984). It is unknown if elephant leiomyoma behave in the same manner, but even if leiomyoma do secrete PRL, this may not be causative for the occurred pseuodpregnancies per se, since a high percentage of Asian elephants exhibit uterine leiomyoma (Montali et al., 1997), but, to our knowledge, this is the first report of PP in elephants. Nonetheless, we suspect a connection between the presences of leiomyomata/inflammation in all 3 elephants that showed prolongation luteal lifespan, but as mentioned above, timing of events may be the decisive factor for the rare occurrence of PP in elephants (ie. only if leiomyoma grow through the endometrium at around 45-55 days post ovulation).

The cases reported here are interesting for another reason. It has been debated whether the pregnancy CLs have the ability to secrete high levels of progestagens throughout an entire pregnancy (Lueders et al., 2012; Stansfield \&Allen, 2012; Yamamoto et al., 2011, 2017). The elephant placenta is incapable of synthesizing steroid hormones, and thus, the source of progestagen for the entire gestation length of 22 months has been questioned. Allen, 2006, suggested that in African elephants, progestagen secretion by the CLs may decline during mid -to late pregnancy as evidenced by reduced activity of $3 \beta$-Hydroxy- $\Delta^{5}$-Steroid Dehydrogenase (3 $\beta$-HSD) detected in the luteal cells (Stansfield \& Allen, 2012). Instead, the 
authors suggested, again on the basis of immunohistochemical staining, that progestagens secreted by the enlarged fetal gonads may accommodate the luteal decline in progestagen secretion. The current Case 2 of pseuopregnancy lasting more than 16 months, may indicate that fetal gonad supplementation of gestagens is not necessary in the Asian elephant within this period of gestation (Fig. 1 b.). The persistent CLs described in all cases also suggest that these were the source of the elevated, circulating progestagens.

Again, it is possible that African and Asian elephants differ in this respect, as they also show marked differences in their progestagen patterns throughout pregnancy (Meyer et al., 2004).

\section{Conclusions}

- Persistent corpora lutea and a state of pseudopregnancy can occur in Asian elephants

- Prolonged luteal activity and elevated progestagen levels may therefore not always be indicative of pregnancy

- Uterine pathologies, especially large growing leiomyoma, or uterine inflammation, may be associated, potentially by triggering stimuli that mimic the maternal recognition of pregnancy signal

- Hyperprolactinemia is described here in an Asian elephant for the first time. In contrast to the African species, hyperprolactinemia in an Asian elephant was not related to acyclicity, but may have prevented luteal regression, thereby leading to prolonged luteal function and pseudopregnancy.

Declarations of interest: The authors declare no conflict of interest.

\section{Acknowledgement}

We express our gratitude to Dr. A. F. Parlow and the National Institute of Diabetes and Digestive and Kidney Diseases (Torrance, CA, U.S.A.) for providing PRL RIA materials. We thank the Japan Society for the Promotion of Science (JSPS) for their support of this research which allowed sample analysis in Tokyo, Japan for prolactin (grant \# PE 11016). We thank Prof. W.R. Allen for valuable input. 


\section{References}

Bechert, U. S., Swanson, L., Wasser, S. K., Hess, D. L., Stormshak, F., 1999. Serum prolactin concentrations in the captive female African elephant (Loxodonta africana): potential effects of season and steroid hormone interactions. Gen. Comp. Endocrin., 114(2), 269-278.

Brown, J. L., Lehnhardt, J., 1997. Secretory patterns of serum prolactin in Asian (Elephas maximus) and African (Loxodonta africana) elephants during different reproductive states: comparison with concentrations in a noncycling African elephant. Zoo Biol. 16(2), 149-159.

Carden, M., Schmitt, D., Tomasi, T., Bradford, J., Moll, D., Brown, J., 1998. Utility of serum progesterone and prolactin analysis for assessing reproductive status in the Asian elephant (Elephas maximus). Anim. Reprod. Sci. 53(1), 133-142.

Chang, K., Kurtz, H. J., Mirocha, C. J., 1979. Effects of the mycotoxin zearalenone on swine reproduction. Am. Journal Vet. Res. 40 (9), 1260-1267.

Clamon Schulz, L., Nelson, R. A., Pyter, L. M., Bahr, J. M., 2003. Induction of pseudopregnancy in the American black bear (Ursus americanus). J. Exp. Zool. Part A: Comp. Exp. Biol. 298(2), 162-166.

Concannon, P. W., Castracane, V. D., Temple, M., Montanez, A., 2009. Endocrine control of ovarian function in dogs and other carnivores. Anim. Reprod. 6(1), 172-193.

Creel, S.R., Montfort, S.L., 1991. Spontaneous lactation is an adaptive result of pseudopregnancy. Nature 351, 660.

Day, A., Jurkovic, D., 2012. The role of ultrasound in early pregnancy after assisted conception, in: Pregnancy after assisted reproductive technology. Jauniaux, E.R.M., Rizk, B.R.M.B. Cambridge Univ. Press, Cambridge, pp. 51-68.

Daly, D. C., Walters, C. A., Prior, J. C., Kuslis, S. T., Chapitis, J., Andreoli, J., Riddick, D. H., 1984. Prolactin production from proliferative phase leiomyoma. Am. J. Obstet. Gyn., 148(8), 1059-1063.

Del Alamo, M. R., Reilas, T., Kindahl, H., Katila, T., 2008. Mechanisms behind intrauterine device-induced luteal persistence in mares. Anim. Reprod. Sci. 107(1), 94-106.

DeHoff, M. H., Stoner, C. S., Bazer, F. W., Collier, R. J., Kraeling, R. R., Buonomo, F. C., 1986. Temporal changes in steroids, prolactin and growth hormone in pregnant and pseudopregnant gilts during mammogenesis and lactogenesis. Dom. Anim. Endocrin. 3(2), 95-105.

Dow, T. L., Brown, J. L., 2012. Evidence that hyperprolactinaemia is associated with ovarian acyclicity in female zoo African elephants. Reprod. Fert. Dev. 24(8), 1019-1027. 
Everett, J. W., 1961. The mammalian female reproductive cycle and its controlling mechanisms. Sex and Int. Sec. 1, 497-555.

Gobello, C., De La Sota, R. L., Goya, R. G., 2001a. A review of canine pseudocyesis. Reprod. Dom. Anim. 36(6), 283-288.

Gobello, C., Concannon, P. W., Verstegen, J., 2001b. Canine Pseudopregnancy: A Review, in: Recent Advances in Small Animal Reproduction. Concannon, P. W., England, G., Verstegen, J. (Eds.) International Veterinary Information Service (www.ivis.org), Ithaca, New York, USA. https://pdfs.semanticscholar.org/ffde/935c30652e46ed30693a3e1d166b67d03519.pdf (accessed March 18th, 2018)

Guedes, D., Young, R. J., 2004. A case of pseudo-pregnancy in captive brown howler monkeys (Alouatta guariba). Folia Primatol. 75(5), 335-338.

Graham, L., Schwarzenberger, F., Möstl, E., Galama, W., Savage, A., 2001. A versatile enzyme immunoassay for the determination of progestogens in feces and serum. Zoo Biol., 20(3), 227-236.

Heap, R. B., Whyte, A., Salamonsen, L.,Wang, M. W., 1989. Comparative studies of the maternal recognition of pregnancy. Eq. Vet. J. 21(S8), 1-6.

Hilliard J., 1973. Corpus luteum function in guinea pigs, hamsters, rats, mice and rabbits. Biol Reprod. 8(2), 203-221.

Hildebrandt, T., Drews, B., Gaeth, A. P., Goeritz, F., Hermes, R., Schmitt, D., Gray, C., Rich, P., Streich, W.J., Short, R.V., Renfree, M. B., 2007. Foetal age determination and development in elephants. Proc Roy Soc London B: Biol. Sci. 274(1608), 323-331.

Josimovich J. B., 1968. Maintenance of pseudopregnancy in the rat by synergism between human placental lactogen and chorionic gonadotrophin. Endocrinology 83(3), 530-543.

Kasza, L., 1979. False pregnancy in a chimpanzee from the zoo in Veszprem. Allattani Kozlemenyek 66, 217-218.

Lawler, D. F., Evans, R. H., Reimers, T. J., Colby, E. D., \& Monti, K. L., 1991. Histopathologic features, environmental factors, and serum estrogen, progesterone, and prolactin values associated with ovarian phase and inflammatory uterine disease in cats. Am. J. Vet. Res. 52(10), 1747-1753.

Lueders, I., 2018. Elephant pregnancy and parturition: Normal and Abnormal, in: Miller, E., Lamberski, N., Calle, P. (Eds.). Fowler's Zoo and Wild Animal Medicine Vol.9, Chapter 96, Elsevier Saunders, St. Louis, MI, 2018.

Lueders, I., Niemuller, C., Gray, C., Rich, P., Hildebrandt, T. B., 2010a. Luteogenesis during the estrous cycle in Asian elephants (Elephas maximus). Reproduction 140(5), 777-786. 
Lueders, I., Drews, B., Niemuller, C., Gray, C., Rich, P., Fickel, J., Wibbelt, G., Goeritz, F., Hildebrandt, T.B., 2010b. Ultrasonographically documented early pregnancy loss in an Asian elephant (Elephas maximus). Reprod. Fert. Dev. 22, 1159-1165.

Lueders, I., Taya, K., Watanabe, G., Niemuller, C., Gray, C., Yamamoto, Y., Yamamoto, T., Kaewmanee, S., Hildebrandt, T. B., 2011. Role of the double LH peak, luteinizing follicles and the secretion of inhibin for dominant follicle selection in Asian elephants (Elephas maximus). Biol. Reprod. 85, 714-720.

Lueders, I., Niemuller, C., Rich, P., Gray, C., Hermes, R., Goeritz, F., Hildebrandt, T. B., 2012. Gestating for 22 months: luteal development and pregnancy maintenance in elephants. Proc Roy So London B: Biol Sci, rspb20121038.

Matsushima, T., Naoe, H., Soejima, R., 1980.Gonadotropin secreting bronchogenic carcinoma in a woman. Br. J. Dis. Chest. 74, 87-90.

Meyer, J. M., Walker, S. L., Freeman, E. W., Steinetz, B. G., Brown, J. L., 2004. Species and fetal gender effects on the endocrinology of pregnancy in elephants. Gen. Comp. Endocrin. 138(3), 263-270.

Murphy, B. D., 1989. Reproductive physiology of female mustelids. Conserv. Biol. and the black-footed ferret. Yale University press, New Haven, CT, 107-123.

Montali, R. J., Hildebrandt, T., Göritz, F., Hermes, R., Ippen, R., Ramsay, E., 1997. Ultrasonography and pathology of genital tract leiomyomas in captive Asian elephants: implications for reproductive soundness. Verh. Erkrg. Zootiere 38, 253-258.

Niemuller, C. A., Shaw, H. J., Hodges, J. K., 1993. Non-invasive monitoring of ovarian function in Asian elephants (Elephas maximus) by measurement of urinary $5 \beta$ pregnanetriol. J. Reprod. Fet. 99(2), 617-625.

Nowak, R. A., Rein, M. S., Heffner, L. J., Friedman, A. J., Tashjian Jr, A. H., 1993. Production of prolactin by smooth muscle cells cultured from human uterine fibroid tumors. The J. Clin. Endocrin. Metabol. 76(5), 1308-1313.

Roberts, R. M., Xie, S., Mathialagan, N., 1996. Maternal recognition of pregnancy. Biol. Reprod. 54(2), 294-302.

Seyle, H., McKeown, T., 2015. Production of pseudo-pregnancy by mechanical stimulation of the nipples. Proc. Soc. Experim. Biol. Med. 31, 683-687.

Sobrinho, L. G., 2003. Prolactin, psychological stress and environment in humans: adaptation and maladaptation. Pituitary 6(1), 35-39.

Smith, M. S., Freeman, M. E., Neill, J. D., 1975. The control of progesterone secretion during the estrous cycle and early pseudopregnancy in the rat: Prolactin, gonadotropin and steroid levels associated with rescue of the corpus luteum of pseudopregnancy. Endocrinology 96(1), 219-226. 
Smith, M. S., McLean, B. K., Neill, J. D., 1976. Prolactin: the initial luteotropic stimulus of pseudopregnancy in the rat. Endocrinology, 98(6), 1370-1377.

Stansfield, F., Allen, W. R., 2012. Luteal maintenance of pregnancy in the African elephant (Loxodonta africana). Reproduction 143, 845-854.

Tsutsui, T., Stabenfeldt, G. H., 1992. Biology of ovarian cycles, pregnancy and pseudopregnancy in the domestic cat. J. Reprod. Fert. Suppl. 47, 29-35.

Willis, E. L., Kersey, D. C., Durrant, B. S., Kouba, A. J., 2011. The acute phase protein ceruloplasmin as a non-invasive marker of pseudopregnancy, pregnancy, and pregnancy loss in the giant panda. PloS one, 6(7), e21159.

Wilsher, S., Allen, W. R., 2011. Intrauterine administration of plant oils inhibits luteolysis in the mare. Eq. Vet. J. 43(1), 99-105.

Yamamoto, Y., Yamamoto, T., Watanabe, G., Yuto, N., Keio, M., Narushima, E., Katayangagi, M., Najao, R., Morikubo, S., Sakurai, Y., Kaneko, M., Kaewmanee, S., Taya, K., 2010. Prolactin secretion and ovarian function in cycling and non-cycling African female elephants (Loxodonta africana). J. Vet. Med. Sci. 72(7), 845-852.

Yamamoto, Y., Yamamoto, T., Taya, K., Watanabe, G., Stansfield, F. J., Allen, W. R., 2011. Placentation in the African elephant (Loxodonta africana). V. The trophoblast secretes placental lactogen. Placenta 32(7), 506-510.

Yamamoto, Y., Yamamoto, T., Yuto, N., Hildebrandt, T. B., Lueders, I., Wibbelt, G., Shina, O., Mouri, Y., Sugimura, K., Sakamoto, S., Kaewmanee, S., Nagaoka, K., Watanabe, G., Taya, K., 2012. The secretory pattern and source of immunoreactive prolactin in pregnant African (Loxodonta africana) and Asian (Elephas maximus) elephants. Journal of Reprod. Develop. 58(1), 105-111.

Yamamoto, Y., Nagaoka, K., Kamite, Y., Watanabe, G., Allen, T., Stansfield, F., Taya, K., 2017. Different origins of two corpora lutea recovered from a pregnant African elephant (Loxodonta africana). Reprod. Dom. Anim. 52(6), 1138-1141. 